\title{
GINÁSTICA PARA MULHERES NO INSTITUTO DE CULTURA FÍSICA (1928-1937): PRIMANDO PELA GRAÇA E BELEZA
}

\author{
Mônica Fagundes Dantas \\ Universidade Federal do Rio Grande do Sul, Porto Alegre, Rio Grande do Sul, Brasil \\ Janice Zarpellon Mazo \\ Universidade Federal do Rio Grande do Sul, Porto Alegre, Rio Grande do Sul, Brasil \\ Carolina Dias \\ Universidade Federal do Rio Grande do Sul, Porto Alegre, Rio Grande do Sul, Brasil
}

\begin{abstract}
Resumo
O objetivo deste estudo é investigar como se sucedeu a difusão da ginástica em Porto Alegre, tendo como principal cenário o Instituto de Cultura Física (ICF). Considerando que o ICF oferecia atividades ao público feminino, busca-se delinear as concepções de feminilidade subjacentes aos métodos ginásticos ensinados na instituição. Com o amparo dos pressupostos teórico-metodológicos da História Cultural, propõe-se uma versão da história do ICF elaborada a partir de fragmentos da memória social registrados nos jornais e documentos da época. No período de 1928 a 1937, alicerçado nos discursos eugenistas e higienistas, o ICF propiciou o desenvolvimento de uma cultura física e artística que atendia aos ideais da mulher burguesa e moderna.
\end{abstract}

Palavras-chave: Dança. Educação Física. Ginástica. Mulheres.

\section{Introdução}

O Instituto de Cultura Física (ICF) foi fundado em 1928, em Porto Alegre, por Eleonor (Nenê) Dreher Bercht e Philomena (Mina) Black-Eckert. Ao longo dos seus nove anos de existência, o ICF entremeou práticas oriundas dos campos da ginástica e da dança. Alicerçado nos discursos eugenistas e higienistas do século XX e propondo-se a desenvolver no corpo feminino a cultura física adequada à mulher moderna, o ICF encontrou grande receptividade na sociedade porto-alegrense. O jornal Diário de Notícias foi um dos responsáveis pela sua difusão na cidade (DIAS, 2011; DANTAS; DIAS; MAZO, 2013).

As fundadoras do ICF pertenciam a famílias de ascendência alemã que se instalaram no Rio Grande do Sul a partir do século XIX. Mina Black-Eckert era filha de Georg Black, imigrante alemão que desembarcou em Porto Alegre em 1902 e que se tornou referência na prática e no ensino da ginástica e de outras modalidades esportivas (LYRA; MAZO, 2010). Mina Black-Eckert viajou algumas vezes à Alemanha, onde fez sua formação como instrutora de ginástica, tendo também a oportunidade de estudar o Método Dalcroze ${ }^{1}$ e de fazer aulas de

\footnotetext{
${ }^{1}$ Émile Jaques-Dalcroze (Suíça, 1869-1950) desenvolveu um método para o ensino da música, também conhecido como Rítmica ou Eurítmica. Tendo como pressuposto o papel fundamental que o corpo e o movimento de- 
dança inspiradas dos ensinamentos de Mary Wigman ${ }^{2}$. Nenê Dreher Bercht era reconhecida como protetora e admiradora das artes. Assim como Mina Black-Eckert, viajou à Alemanha em meados dos anos 1920 e frequentou aulas de ginástica e dança.

Antes da criação do ICF, Mina Black-Eckert e Nenê Dreher Bercht são apontadas como responsáveis pela organização de um dos primeiros eventos artísticos realizados em Porto Alegre. Em 1925, sob a denominação de Contos de fada, foram apresentados bailados rítmicos executados por elenco de porto-alegrenses (ESPETÁCULO..., C.P., 04/08/1925; CONTOS..., C., 6/8/1925). Entre os anos de 1926 e 1927, Nenê Dreher Bercht e Mina BlackEckert se encontraram na Alemanha, quando planejaram a criação do futuro ICF, onde a ginástica seria a principal prática corporal.

$\mathrm{O}$ artigo tem por objetivo investigar como se sucedeu a difusão da prática da ginástica na cidade de Porto Alegre, tendo como cenário o ICF. Tendo em vista que o ICF foi uma instituição que oferecia atividades ao público feminino, de forma mais específica, buscamos delinear as concepções de feminilidade subjacentes aos métodos ginásticos ensinados no ICF.

Para contemplar tais objetivos, este estudo se ampara nos horizontes teóricometodológicos da História Cultural (CHARTIER, 2000; BURKE, 2005; PESAVENTO, 2008), pois esta permite construir, através da busca de acontecimentos passados e da interpretação de representações de um tempo não vivido, uma versão possível da realidade. Nesta direção, busca-se esboçar uma versão da história elaborada a partir de fragmentos da memória social registrados nos jornais e documentos da época. Foram privilegiados os jornais portoalegrenses de maior circulação na época, como Diário de Notícias (DN), Correio do Povo (CP) e A Federação (A FED), além do Catálogo da Revista do Globo (MAZO, 2004).

As informações coletadas foram submetidas à análise documental (PINSKY, 2008; PIMENTEL, 2001). Neste processo, as fontes escritas foram analisadas com base nos métodos críticos recomendados à investigação historiográfica. De tal modo, busca-se elaborar uma reconstrução crítica de informações que permitam elaborar inferências e uma versão da história. Com o intuito de afinar o olhar sobre o objeto de investigação, além do referencial oriundo da História Cultural, estudos sobre gênero (SCOTT, 1995; LOURO, 1997; GOELLNER, 2007) também embasaram a análise e a interpretação das informações.

A realização do presente estudo almeja contribuir para o campo da História da Educação Física, da Dança e dos Esportes. Consideramos que a reconstituição da trajetória de instituições como ICF permite refletir sobre a produção e a afirmação de práticas corporais e representações culturais que contribuíram para a redefinição de papéis, lugares e imaginários sociais de mulheres pertencentes às classes mais abastadas do ponto de vista econômico na cidade de Porto Alegre, na primeira metade do século XX.

\section{A difusão da ginástica de origem alemã em Porto Alegre e a criação do ICF}

\footnotetext{
sempenham na percepção musical, Dalcroze buscou reavivar o sentimento rítmico por meio da realização de movimentos em acordo com compassos e intervalos musicais. Desse modo, a educação corporal deveria ocorrer através da música, destacando a complementaridade existente entre o desenvolvimento motor e as capacidades mais sensíveis do ser humano. Dalcroze foi nomeado professor de harmonia e solfejo no Conservatório de Genebra em 1892. Após quase 18 anos de atuação, no ano de 1910 foi trabalhar em Hellerau, distrito de Dresden, na Alemanha, onde foi construído um prédio de arquitetura arrojada para sua época - Festpielhaus Hellerau - que abrigava a escola de Dalcroze e um teatro. Em 1915 retornou a Genebra, quando foi fundado o Instituto JaquesDalcroze (MATHIEU, 2010).

${ }^{2}$ Mary Wigman (Alemanha, 1886-1973) atuou como bailarina, professora e coreógrafa. Foi discípula e assistente de Dalcroze. A partir de 1913, começou carreira solo como bailarina, ao mesmo tempo em que desenvolveu uma pedagogia da dança que incluía estudos em improvisação e em composição coreográfica. Fundou sua primeira escola em 1920, na cidade de Dresden, na Alemanha (SUQUET, 2012).
} 
A ocorrência de correntes imigratórias de alemães no Brasil tem início em 1824, sendo direcionada para a região onde hoje se localiza o município de São Leopoldo, no Rio Grande do Sul. Alguns imigrantes não permaneceram nessa localidade, deslocando-se para Porto Alegre. A partir de então e até aproximadamente 1914, começaram a aportar outros grupos de imigrantes alemães que se estabeleceram em diferentes localidades do Estado (VOGT, 2006).

A situação político-econômica da Alemanha no final do século XIX favorecia a emigração. O Brasil, e mais especificamente a região Sul do país, parecia uma terra propícia para a vinda de estrangeiros, que deveriam ocupar o território nacional, pois havia uma vastidão de terras desertas, cobiçadas pelos países vizinhos. De acordo com Schütz (1974), o governo do Rio Grande do Sul simpatizava com a ideia de a terra ser ocupada por estrangeiros europeus e não por escravos negros, visando, assim, ao que se acreditava ser a melhoria da raça brasileira.

As correntes migratórias vindas da Europa foram um dos principais fatores na difusão da prática da ginástica no Brasil. Em Porto Alegre, a presença de imigrantes alemães foi fator decisivo na promoção das práticas corporais (MAZO, 2006). O método ginástico alemão difundiu a ideia de que o desenvolvimento corporal traria benefícios ao corpo e à moral do indivíduo. Do mesmo modo, foi um relevante meio aglutinador de traços que comporiam uma identidade teuto-brasileira. Segundo Oliven (1992), as identidades são construções reais ou inventadas que conferem uma marca de distinção. Quando abordamos a noção de identidade tratamos, do mesmo modo, de identidades etnoculturais a partir das noções teóricas de Cuche (1999). De acordo com este autor, a identidade etnocultural resulta do vínculo primário estabelecido pelos indivíduos com o ambiente que os cerca. Constitui-se como a primeira identificação que ocorre do indivíduo com a sociedade, sendo, portanto, inerente ao grupo. Entretanto, e embora um grupo cultural caminhe no sentido do estabelecimento de "fronteiras de identidades" (p. 200) simbólicas, pode ainda estabelecer relação com outras culturas, ressignificando e incorporando fragmentos de uma cultura estrangeira.

A difusão do sistema ginástico alemão em Porto Alegre ocorreu em estreita relação com a criação das primeiras associações ${ }^{3}$ esportivas e culturais pelos imigrantes alemães, em meados do século XIX. Ao se transferirem para o Brasil, estes imigrantes portavam um habitus $^{4}$ característico de sua cultura. A partir do momento em que se estabilizavam e começavam a dinamizar sua vida social, procuravam meios de manter e difundir a cultura de sua terra de origem, através, principalmente, da criação de espaços destinados ao lazer e a sociabilidades. Além da ginástica, as associações promoviam atividades variadas como o canto, a leitura, o esporte e a dança. Tinham também por intuito formar redes solidárias para ajudar os membros de suas comunidades. Assim, a estruturação de diversos clubes, ligas e federações, bem como a difusão de práticas corporais como a ginástica, figura como uma estratégia de aquisição de espaços sociais por este grupo étnico (MAZO, 2006).

A primeira sociedade de ginástica do Rio Grande do Sul de identidade teuto-brasileira, a Turnerbund $^{5}$ (SILVA, 1997), foi criada em 1867, em Porto Alegre. A ginástica foi a primeira prática corporal desenvolvida por esta instituição (DAUDT, 1942). A participação das mulheres nas práticas corporais oferecidas pela Turnerbund deu-se a partir do início do século

\footnotetext{
${ }^{3}$ Para Labra e Figueiredo (2002), há uma característica corporativa na criação de associações, por indivíduos que têm interesses em comum e princípios que guiarão a ação coletiva.

${ }^{4} \mathrm{O}$ habitus, nesta pesquisa, é estendido como um "saber social incorporado" ou então encarado como uma "segunda natureza". Segundo Elias (1997, p. 9), a categoria de habitus se refere à "[...] composição social dos indivíduos, como que constitui o solo de que brotam as características pessoais mediante as quais um indivíduo difere dos outros membros da sociedade. Dessa maneira, alguma coisa brota da linguagem comum que o indivíduo compartilha com os outros e que é certamente um componente do habitus social - um estilo mais ou menos individual, algo que poderia ser chamado de grafia individual inconfundível que brota da escrita social".

${ }^{5}$ Atual Sociedade Ginástica de Porto Alegre, 1867, conhecida como SOGIPA.
} 
XX. Em 1904, as mulheres adquiriram o direito de fazer o curso de instrutoras e obter a "mesma" distinção que os homens. As primeiras a receberem o título de mestre de ginástica foram: Ella Kaufmann, Frieda Naschold, Emma Scheibenzuber e Hermine Grage. Nesse mesmo ano, foi criado o departamento feminino de ginástica. $\mathrm{O}$ departamento contava com 37 mulheres classificadas como casadas e solteiras, sendo que as mulheres casadas iniciaram as sessões de ginástica em 1907 (DAUDT, 1942). Essas informações evidenciam que, embora houvesse certa resistência de alguns associados, as mulheres conquistaram espaços décadas após a criação da Turnerbund.

Em 1905, a direção do departamento feminino foi entregue ao professor de ginástica da sociedade Turnerbund, que ministrava "Educação Física para moças". Entretanto, as mulheres seguiram realizando a formação em ginástica, a exemplo de três alemãs. Na década de 1920, mais cinco mulheres se formaram mestres de ginástica e, na década seguinte, este número foi ampliado, quando se formaram 19 mestras de ginástica (DAUDT, 1942). Dentre as instrutoras formadas pela Turnerbund nesse período, encontrava-se Nenê Dreher Bercht, a diretora artística do ICF.

O desenvolvimento da cultura física feminina alicerçada na prática da ginástica, para além da afirmação de uma identidade teuto-brasileira, era parte das campanhas com finalidades eugênicas e higiênicas propagadas por médicos e intelectuais no início do século XX. Visando ao fortalecimento da raça e ao desenvolvimento saudável dos cidadãos da jovem república brasileira, essas campanhas passaram a incluir as mulheres. A imprensa escrita se tornou uma das principais fontes de divulgação da nova cultura física feminina, incentivando a criação de espaços destinados a este fim (SCHPUN, 1999).

Em Porto Alegre, o incentivo ao desenvolvimento da cultura física feminina desencadeia-se no final dos anos 1920. Em 1928, Sevenor Muniz, uma jovem senhora formada pela Escola Normal de São Paulo, fundou a Liga Feminina em Prol da Cultura Física. O livro de adesões à liga trazia a seguinte inscrição: "Impulsionadas pelo ideal de aperfeiçoamento physico de nosso povo fundamos o Instituto Feminino de Cultura Física" (EDUCAÇÃO..., C.P., 28/3/1928). Em seu texto, publicado pelo jornal Correio do Povo, Muniz se diz motivada pela "[...] divulgação da educação physica das nossas patrícias" (EDUCAÇÃO..., C.P., 28/03/1928). Muniz proclama que todo aquele que se unir a essa causa, concorrendo moralmente ao êxito do instituto, teria o direito de se considerar um verdadeiro patriota. Estes fragmentos extraídos do jornal sugerem que havia uma preocupação com a prática de Educação Física pelas mulheres, justificando-se por meio de um discurso atravessado pelos valores que apontam para um processo de construção de uma identidade nacional brasileira. E, nesse processo atravessado pela negociação de identidades culturais, a ginástica, embora alvo de resistência, era vista como uma das práticas que contribuiria para a melhoria da raça brasileira.

O Instituto Feminino de Cultura Física se dedicava, principalmente, ao ensino da ginástica, pois esta se tratava de uma atividade indispensável para a formação de uma raça forte, que faria do país uma nação poderosa (EDUCAÇÃO..., C.P., 28/3/1928). Muniz tinha a intenção de filiar a instituição à Federação Rio-Grandense de Desportos ${ }^{6}$, para que houvesse mais incentivo ao desenvolvimento da Educação Física feminina. Entretanto, em outra publicação veiculada pelo jornal Correio do Povo, esclarecia que suas ideias estavam longe de transformar as "gentis gaúchas" em competidoras com o "sexo forte". Sua intenção era fazêlas fortes, desenvoltas, plenas de graça e delicadeza (MUNIZ, 29/3/1928).

Os motivos que levaram ao encerramento das atividades do Instituto Feminino de Cultura Física não são conhecidos. O instituto, ao tentar vincular-se à federação esportiva, talvez aludiu a uma representação cultural da prática de esportes pelas mulheres. Esta iniciativa pode

\footnotetext{
${ }^{6}$ Esta entidade foi fundada em 1918 contemplando vários esportes. Posteriormente, privilegiou exclusivamente o futebol e passou a ser denominada Federação Gaúcha de Futebol (MAZO, 2012). 
ter gerado um conflito, pois os esportes eram uma prática mais direcionada aos homens no período. Sabe-se, no entanto, que em 1928 Mina Black-Eckert e Nenê Dreher Bercht fundaram, em Porto Alegre, o Instituto de Cultura Física. O ICF recebeu o incentivo do crítico de arte Ângelo Guido. Em 1929, ele criou a sessão "Para o aperfeiçoamento da raça", no jornal Diário de Notícias, na qual descreve o ICF como uma instituição com "[...] alta finalidade educativa [...] incentivando a raça a amar as coisas belas e nobres" (GYMNASTICA..., D.N., 4/8/1929, p. 16). O ICF surge como um espaço modelador tanto das formas físicas quanto da moral feminina. Para Ângelo Guido, Porto Alegre necessitava de um local como este, pois “[...] se tratava não só do fortalecimento, mas também do aformoseamento da raça brasileira, coisa que a muito já se fazia em outros países, como na Alemanha, onde o problema da cultura já havia se tornado uma das grandes preocupações do governo" (GYMNASTICA..., D.N., 4/8/1929, p. 16).

A fundação do ICF inseria-se num movimento político-cultural que encontrava apoio entre intelectuais e pessoas ilustres do Brasil de então. Do continente europeu importavam-se modelos de conduta e educação destinados a incentivar o progresso e potencializar o crescimento do novo país republicano, buscando inseri-lo na lógica do mercado capitalista. De fato, tais projetos visavam à edificação e ao fortalecimento da nação brasileira, iniciados em 1910 (BOMEDY, 1993).

Em acordo com Schpun (1999), poderíamos associar a criação do ICF à necessidade de uma elite feminina burguesa que, por circular mais pelas ruas da cidade, ansiava por frequentar novos espaços de sociabilidade. Talvez este seja um dos motivos pelos quais, sete meses após sua criação, o ICF já contava com cerca de 150 alunas matriculadas. Um ano após a fundação, em julho de 1929, havia 250 alunas matriculadas, entre "senhoras e senhoritas" (GUIDO, 28/7/1929), que frequentavam aulas de ginástica.

\section{As ginásticas no ICF: ritmo, graça e beleza}

O ICF foi fundado com o intuito de propiciar o incremento físico e o desenvolvimento da plasticidade gestual feminina. Entre o final do século XIX e início do século XX, a ginástica alemã era a prática corporal predominante para as mulheres de ascendência alemã (BEGOSSI; MAZO, 2015). No entanto, o início do século XX acentuou uma visão de que os cuidados com o corpo deveriam ir além do desenvolvimento físico, englobando, inclusive, o desenvolvimento plástico e rítmico dos praticantes. Nestes contornos, além das funções medicalizantes que os sistemas ginásticos ofereciam, agregou-se mais uma incumbência: a inclusão do ritmo e o desenvolvimento das faculdades sensíveis do indivíduo, em particular, das mulheres (PFISTER, 2006; BAZOGE, 2016).

Em 1929, Ângelo Guido transcreveu no Diário de Notícias (UMA OBRA..., 11/08/1929) um trecho do artigo de Claire Patek, no qual a autora enfatizava a utilização de exercícios rítmicos e fazia um alerta às mulheres para que evitassem buscar a beleza por meio, apenas, da prática esportiva: "falha nas suas finalidades pelo embrutecimento das formas e dos movimentos. [...] entretanto se reunirmos o desporto ao exercício rythmico, terse-á o que de mais bello se pode imaginar". O texto de Patek foi publicado pela primeira vez na revista alemã Sonnige Wlet, que veiculava informações acerca da cultura física feminina. Suas ideias ratificavam as matérias do Diário de Notícias e da Revista do Globo (MAZO, 2004), as quais proclamavam que os exercícios rítmicos seriam os mais adequados às mulheres. Segundo Ângelo Guido, as diretoras do ICF, "que tantos valiosos serviços vinham prestando à mocidade feminina da capital", tinham opinião semelhante à sua, no que se refere às atividades físicas recomendadas às mulheres. É provável que tais preocupações e recomendações anunciadas às mulheres sejam um indício de que já havia mulheres inseridas na prática esportiva, contrariando certo ideal de feminilidade gestado entre os séculos XVII e XVIII, o qual prescrevia 
restrições à participação das mulheres em exercícios considerados rudes, como também em atividades que provocassem intensa agitação corporal. Já entre o século XIX e início do século XX, ocorre um incentivo à prática de atividades que desenvolvessem as características físicas concernentes ao gênero feminino, como seria o caso da ginástica rítmica. No entanto, estudos sobre a história do corpo trazem vestígios de que, desde o século XVIII, o ideal de beleza feminina busca uma aproximação maior com uma concepção de corpo saudável associada a atividades realizadas ao ar livre que proporcionassem ao corpo feminino mais tonicidade e agilidade (PFISTER, 2006; VIGARELLO, 2008; BAZOGE, 2016).

De acordo com o Diário de Notícias (GYMNASTICA..., 04/8/1929) os exercícios do ICF eram destinados a corrigir a respiração, bem como os defeitos provenientes de maus hábitos das mulheres. Tais correções iam da melhora do ato de locomover-se ao desenvolvimento dos estudos rítmicos. Para isso, as aulas do ICF propunham uma série de exercícios rítmicos que levariam as alunas a adquirir elegância, graça e leveza durante o deslocamento. Dentre as críticas direcionadas às moças que ainda não haviam incorporado a cultura física, estava o ato de levantar o joelho ao andar. Comparado ao padrão estabelecido na época, esse "defeito" no caminhar entortava as pernas das mulheres e fazia com que fosse raro encontrar "joelhos bem feitos". Enfatizando tal crítica, Ângelo Guido escreve: "[...] uma coisa curiosa nota-se frequentemente: ás vezes uma mulher tem pernas bonitas, mas os joelhos são um desastre" (GYMNASTICA...D.N., 4/8/1929, p. 16).

Schpun (1999) ressalta que, nos textos de Fernando de Azevedo, era recorrente a referência ao caminhar das mulheres. Visto que se tratava de um corpo feminino que desfilava constantemente diante do olhar dos homens, seja nas ruas, lojas e espaços de lazer, o caminhar deveria ser imbuído de graça. Deveriam elas investir na desenvoltura do seu andar que, agora, era alvo de novas atenções e, portanto, de novas vigilâncias. Adquirir postura, plasticidade e um corpo desejável, a partir do ingresso em espaços como o ICF, significava também incorporar mais um dote - como o canto, o piano, a pintura - que aumentaria o status social e melhoraria as chances de se conseguir um bom casamento. Defendia-se que "a moça que alcançasse, pela ginástica, um desenvolvimento integral estaria, assim, multiplicado seus encantos, tornando-se um ser desembaraçado, vivaz e com uma simpatia incalculável" (GYMNASTICA..., 04/08/1929, p. 16). Nesse sentido, os textos de Fernando de Azevedo enalteciam a beleza necessária ao corpo da mulher, apresentando a Educação Física como possibilidade de aquisição destes novos padrões estéticos.

Dentre as práticas que eram desenvolvidas no ICF estavam a Ginástica Corretiva, a Ginástica Rítmica, a Plástica Animada, a Ginástica Geral e os Estudos e Improvisações Coreográficas. No entanto, a Ginástica Rítmica constituía a principal referência no seu programa educativo (DANTAS, DIAS, MAZO, 2013), afirmando-se como uma prática corporal que transitava entre a ginástica e a dança da época. O ICF não era uma escola de dança clássica, mas os ideais da dança permeavam o fazer ginástico, de modo que seu programa educativo culminava nessa arte. A promessa era de que a aluna que completasse o curso, além do seu desenvolvimento físico integral alcançaria a beleza dos seus gestos e a harmonia de movimentos que são próprios da dança (GYMNASTICA..., 04/08/1929).

O primeiro documento de divulgação do ICF, redigido em alemão, explicava que, inicialmente, se primava pelo desenvolvimento do sentimento. Paralelo ao primeiro contato com os trabalhos de expressão corporal, ressaltava-se a importância da aquisição de ritmo através dos trabalhos de solfejo chamados de Singspiel. As descrições apresentadas por este primeiro programa demonstravam a forte presença do Método Dalcroze, visto que estava inclusa nos exercícios de aquisição rítmica a representação corporal de notas musicais. O Método Dalcroze se sustenta em três pilares: rítmica, solfejo e improvisação. A rítmica se dedica às relações espaço-temporais comuns ao movimento e à música, privilegiando a escuta e a realização de movimentos. O solfejo visa ao trabalho com movimentos corporais aliados a vocali- 
zações. A improvisação envolve atividades vocais, instrumentais e de movimentos corporais, visando ao desenvolvimento da criatividade e da expressão (MEAD, 1986; HABRON, 2014). Estas práticas foram adaptadas à perspectiva de ensino do ICF e estavam presentes, mesmo que com outras denominações, nas aulas ministradas por suas instrutoras (DANTAS; MAZO; DIAS, 2013).

Embora a ginástica rítmica se constituísse como o eixo central da abordagem pedagógica do ICF, outros tipos de ginástica também eram ensinados, com destaque para a ginástica geral e corretiva, herdeiras da ginástica sueca ${ }^{7}$. O Diário de Notícias destaca: "[...] a gymnastica rythmica inclue a gymnastica correctiva, respiratória e acrobática, etc. e a sua acção não se limita ao desenvolvimento muscular, mas se afunda, por assim dizer até o ser psychico e actua sobre os sentimentos como sobre o intellecto" (DO VALOR..., 1929). Estas outras ginásticas eram consideradas a base para o desenvolvimento corporal das alunas, pois visavam à correção postural; no entanto, não eram suficientes para o desenvolvimento integral do corpo feminino. Era necessária uma ginástica que cultivasse a sensibilidade e o intelecto, como podemos ler no Diário de Notícias: "A Ginástica Rítmica surge como um novo método de educação que era diferente das outras ginásticas por ser considerada, ao mesmo tempo, como ciência e como arte" (DO VALOR..., 1929).

No ICF, as aulas se organizavam em grupos de cinco, dez ou mais alunos. Poderiam ocorrer aulas individuais, quando indicadas pelas professoras, ou então extras, visando à formação de futuras instrutoras. No programa de ensino do ICF, constavam quatro turmas, cada qual com um currículo diferente. De acordo com Ângelo Guido (GUIDO, 1929), o curso completo e a ordenação das turmas ocorriam da seguinte forma: a primeira turma identificada como "Curso/classe I a", na qual eram ensinados os exercícios preliminares de ginástica; a segunda turma, "Curso/classe I b", em que se desenvolviam ginástica respiratória e corretiva, ginástica rítmica e estudos coreográficos; a terceira turma, também denominada "Curso/classe I b", trabalhava exclusivamente a ginástica rítmica; a quarta turma, "Curso/classe II a", na qual eram ensinados ginástica em geral, ginástica rítmica, movimentos plásticos, improvisação própria de coreografia e estudo coreográfico. As aulas eram acompanhadas de diferentes instrumentos musicais, como tambores e bastões, mas, na maioria das vezes, utilizava-se o piano. No ICF, eram desenvolvidas práticas corporais muito similares à dança, principalmente pelo fato de no programa de ensino constar como objetivo promover trabalhos de improvisações e estudos coreográficos. Entretanto, estes eram meios de desenvolver a leveza e a graça juntamente com o despertar do ritmo e do sentido estético (CUNHA; FRANK, 2004). Tais fatos corroboram a aproximação entre o programa de ensino do ICF e o Método Dalcroze. Em ambos, sempre houve uma atenção para a ilustração de peças do repertório musical através da realização de movimentos e deslocamentos do corpo no espaço, aproximando-se da realização de coreografias. De acordo com Habron (2015), a aplicação do Método Dalcroze supõe a realização desse tipo de estudo coreográfico-musical, no qual os aprendizes reúnem e aplicam os conhecimentos desenvolvidos durante sua formação ${ }^{8}$.

\footnotetext{
${ }^{7} \mathrm{Na}$ mesma época em que vertentes da ginástica sueca, também conhecida como "Ginástica de Ling", eram ensinadas no ICF, o inspetor de Educação Física da Diretoria Geral da Instrução Pública do Estado do Rio Grande do Sul, professor Frederico Guilherrme Gaelzer, era um árduo seguidor do Método Sueco de Ginástica, preconizado por Per Henrik Ling em seus discursos sobre a Educação Física nas escolas (BEGOSSI, 2017). Inclusive, na condição de professor e inspetor de Educação Física, o professor Gaelzer participou de evento sobre a ginástica sueca, em Estocolmo (Suécia), na década de 1930, além de outros eventos na Europa, como no Congresso de Educação Física e Recreação, realizado na Escola de Educação Física de Charlottemburg em Berlim (Alemanha), Copenhague (Dinamarca), Joinville-le-Pont (França) e Hellerau (Luxemburgo). A pesquisa de Begossi (2017) mostrou que a recepção e a circulação dos saberes da ginástica sueca também ocorreram nos Cursos Intensivos de Educação Física, coordenados pelo professor Gaelzer na década de 1930, e na disciplina de Pedagogia e suas práticas, oferecida pelo Curso Normal da ESEF, na década de 1940.

${ }^{8} \mathrm{O}$ método Dalcroze é praticado e ensinado até hoje, em instituições como Institut Jaques-Dalcroze (Suíça),
} 
O acompanhamento musical realizado nas aulas do ICF era transportado para as apresentações públicas nos teatros da cidade, as quais eram realizadas com a presença de orquestra composta por piano, violinos e violoncelos. Desde o primeiro ano de sua fundação, o ICF realizava espetáculos em espaços consagrados pela elite porto-alegrense, como o Teatro São Pedro, tendo realizado ao menos um espetáculo por ano. Em 1928, foi exibido o primeiro espetáculo da instituição no festival promovido pelo Teatro São Pedro, intitulado Hora de Arte (HORA..., D.N., 23/11/1928). As alunas que participavam das apresentações tinham seus nomes divulgados nos anúncios e nas descrições dos programas, acompanhando, respectivamente, os números nos quais estariam presentes. O grupo de alunas era dividido como meninas e senhoritas, o que dá a entender que as senhoras, mulheres casadas, não participavam dos espetáculos. Na apresentação da "Hora de Arte", as alunas da classe "senhoritas" executaram um programa em três atos. O primeiro ato era composto por sequências de ginástica acrobática e ginástica rítmica, ambientadas em uma cena inspirada na Grécia Antiga. Ainda no primeiro ato, foram apresentados estudos de expressão, provavelmente inspirados nos movimentos plásticos. No segundo ato, foram exibidas coreografias com diferentes temas (INSTITUTO..., C.P., 17/11/1928). Os comentários na imprensa foram promissores, destacando que o ICF “[...] realisou ante-ontem [...] uma interessante hora de arte [...] na sua mais bella expressão: a plastica viva e a choregraphia, [...] procurando, com exito, dar á cultura physica esse alto cunho esthetico, em que se casam graça e energia expressiva, dominadas pelo rhytmo, prestanos o mais relevante serviço" (HORA..., C.P., 20/11/1928).

A primeira fase do ICF, que vai de 1928 a 1930, foi o momento em que a instituição encontrou maior repercussão na cidade de Porto Alegre, principalmente pelas inovações que estavam sendo instauradas no campo das práticas corporais femininas, inspiradas pelo Método Dalcroze. Neste período, a sociedade local via no ICF uma filial do Instituto Jaques-Dalcroze, conferindo-lhe o status de uma instituição eminentemente europeia. Este contexto impulsionou a preferência do público feminino por métodos que levassem à aquisição da boa forma física e da graciosidade. Como soluções a estes desejos, eram oferecidas no ICF práticas pertinentes ao período e que estavam incluídas também neste processo de transformação e instituição da dança na cidade de Porto Alegre.

É preciso ressaltar, concordando com Suquet (2012), que, na Alemanha e na Europa em geral, centros como o Instituto Jaques-Dalcroze e suas "filiais" foram lugares de experimentação, tanto pedagógicas quanto artísticas ou teóricas. Combatida, consentida ou cultivada, a ambiguidade entre dança e ginástica rítmica foi uma constante ao longo dos anos 1920 . Desse modo, enquanto o ritmicista e ginasta Rudolf Bode ${ }^{9}$ criou a ginástica expressiva ( $A u s$ druckgymnastik), aparentada à dança, Mary Wigman, já consagrada como dançarina, desenvolveu uma forma de ginástica dançada (Tanz-gymnastik), aparentada à ginástica.

As práticas corporais, para além da diferenciação de gênero, eram também um modo de perpetuar uma forma de ser (VIGARELLO, 2008). Mesmo apresentando mudanças na constituição das atividades físicas ao longo dos tempos, as elites representadas pela nobreza europeia utilizavam as práticas corporais e esportivas para mostrar "[...] uma aparência, um porte, para lembrar uma pertença" (VIGARELLO, 2008, p. 316). Entre os séculos XVI e XVII, como hábitos esportivos que compunham o programa educativo de um fidalgo, estavam

Rythmique - Institut Dalcroze Belgique (Bélgica), Dalcroze Society of America, Institute for Jaques-Dalcroze Education, The Dalcroze School of the Rockies (Estados Unidos da América), Long School of Music of Bard College (Reino Unido), entre outras, as quais oferecem formação e certificação no Método Dalcroze. Do mesmo modo, pesquisadores têm se dedicado a estudar a pertinência e a atualidade das proposições de Dalcroze, registradas em publicações (HABRON, 2014, 2015; MATHIEU, 2010), e eventos acadêmicos internacionais, como as três edições da International Conference of Dalcroze Studies (HABRON, 2015, 2016; HABRON; MATHIEU, 2017).

${ }^{9}$ Rudolf Bode (Alemanha,1881-1970) fez sua formação com Émile Jaques-Dalcroze. Em 1911, fundou sua Escola de Ginástica Rítmica em Munique. Em 1922, publicou o livro Ausdruckgymnastik. 
presentes atividades destinadas ao aperfeiçoamento do gesto e da postura corporal, desenvolvidas através da dança.

No início do século XX, em Porto Alegre, fazer parte do ICF para construir um corpo esbelto e forte, lapidar seus gestos, desenvolver sua sensibilidade, seu sentido rítmico e estético era uma estratégia de distinção que anunciava a pertença a um grupo social específico. Embora as campanhas de aperfeiçoamento e melhoramento da raça, que estimulavam a incorporação da saúde e da beleza corporal, fossem para todo o povo, para a grande nação, somente as mulheres que pertenciam à elite social tinham condições de pagar para frequentar um espaço privado como o ICF.

\title{
Considerações finais
}

Com a difusão dos ideais oriundos do Iluminismo, a partir do século XVIII, emergem novas concepções pedagógicas nas quais o corpo, a saúde e a Educação Física desempenham um papel significativo. Ainda que tais concepções englobassem a educação de homens e mulheres, as atividades físicas indicadas para homens eram diferentes daquelas indicadas para mulheres. No século XIX e início do século XX, incentivavam-se as mulheres a praticarem atividades que desenvolvessem as características físicas concernentes ao gênero feminino. Assim, a ginástica e, principalmente, a ginástica rítmica se tornaram a modalidade mais indicada às mulheres.

A instituição dos projetos que defendiam maior atenção à forma física dos jovens, com preocupações higiênicas, eugênicas, disciplinares e médicas, como era o caso da ginástica, baseava-se, desde o início, em uma nítida distinção entre as práticas aconselhadas a cada sexo. Para as mulheres, mesmo que pudessem praticar outro esporte, a ginástica era sempre indicada por ser desprovida de sentimentos de agressividade e competitividade e por não promover a ambição individual, elemento inerente ao processo de socialização dos meninos e descartado no das meninas.

Em Porto Alegre, o ICF se constituiu como um espaço que visava desenvolver, através de práticas corporais alicerçadas na ginástica e na dança, a plasticidade e a feminilidade da mulher do início do século XX. O ICF propiciava às mulheres da elite burguesa o desenvolvimento de uma cultura física e artística que atendia aos ideais de uma mulher moderna: saudável, bela, graciosa, elegante. Em suma, feminina.

\section{GYMNASTICS FOR WOMEN AT INSTITUTE OF PHYSICAL CULTURE (1928- 1937): EXCELLING BY GRACE AND BEAUTY}

\begin{abstract}
The aim of this study is to investigate how it came to spread gymnastics in Porto Alegre, with the main scenario at the Institute of Physical Culture (IPC). Considering that the IPC was an institution that offered activities to the women public, we seek to outline the femininity concepts underlying the gymnastic methods taught in the IPC. Bolstered in theoretical and methodological horizons of Cultural History, the study proposes a version of the history of IPC drawn from the social memory fragments recorded in the papers and documents of the time. In the period 1928-1937, based on eugenics and hygienists speeches, IPC led to the development of a physical and artistic culture that served the ideals of bourgeois modern woman.
\end{abstract}

Keywords: Dance. Physical Education. Gymnastic. Women. 


\section{GIMNASIA PARA MUJERES EN EL INSTITUTO DE CULTURA FÍSICA (1928- 1937): SOBRESALIENDO POR LA GRACIA Y LA BELLEZA}

\section{Resumen}

El objetivo del estudio es investigar la difusión de la Gimnasia en Porto Alegre, teniendo como principal escenario el Instituto de Cultura Física (ICF). Dado que el ICF fue una institución que ofrecía actividades al público femenino, se procura delinear las concepciones de feminidad subyacentes a los métodos gimnásticos enseñados en el ICF. Apoyado en la Historia Cultural, el estudio propone una versión de la historia del ICF elaborada a partir de fragmentos de la memoria social registrados en diarios y documentos de la época. En el período de 1928 a 1937, fundamentado en los discursos eugenésicos e higienistas, el ICF condujo el desarrollo de una cultura física y artística que respondía a los ideales de la mujer burguesa y moderna.

Palabras clave: Danza. Educación Física. Gimnasia. Mujeres.

\section{Referências}

BAZOGE, N. La gymnastique d'entretien au XXe siècle : d'une valorisation de la masculinité hégémonique à l'expression d'un féminisme en action. Clio. Histoire, femmes et sociétés, n. 26, 2016, p. 197-208. Disponível em <http://clio.revues.org/1900>. Acesso em: 5 de set. 2017.

BEGOSSI, T. D.; MAZO, J. Z. Ginástica alemã e ginástica feminina moderna: práticas destinadas às mulheres. Cinergis, 2015.

BEGOSSI, T. D. A construção dos saberes disciplinares do Curso Normal da Escola Superior de Educação Física do estado do Rio Grande do Sul (1940-1956). 2017. Dissertação (Mestrado em Ciências do Movimento Humano) - Escola de Educação Física, Fisioterapia e Dança, Universidade Federal do Rio Grande do Sul, Porto Alegre, 2017.

BURKE, P. O que é história cultural. Rio de Janeiro: Zahar, 2005.

BOMEDY, H. Novos talentos, vícios antigos: Os renovadores e a política educacional. Estudos Históricos - Os anos 20. Rio de Janeiro, v. 6, n. 11, p. 24-39, 1993.

CHARTIER, R. A história cultural: entre práticas e representações. Lisboa: DIFEL, 2000.

CONTOS de fadas, no theatro são pedro. Correio do Povo. Porto Alegre, 6 ago.1925. [s.p.].

CUCHE, D. A noção de cultura nas ciências sociais. Bauru: EDUSC, 1999.

CUNHA, M.; FRANK, C. F. Dança: nossos artífices. Porto Alegre: Movimento, 2004.

DANTAS, M. F.; DIAS, C.; MAZO, J. Z. O Instituto de Cultura Física de Porto Alegre/RS e sua práticas corporais (1928-1937). Movimento, Porto Alegre, v. 9, n.1, p. 33-53, jan./mar., 2013.

DAUT, J. Álbum comemorativo ao $75^{\circ}$ aniversário da Sociedade Ginástica de Porto Alegre. Porto Alegre: SOGIPA, 1942. 
DIAS, C. Histórias do Instituto de Cultura Física de Porto Alegre (1928-1937). 2011. Dissertação (Mestrado em Ciências do Movimento Humano) - Escola de Educação Física, Universidade Federal do Rio Grande do Sul, Porto Alegre, 2011.

DO VALOR da cultura physica para a educação de menores anormaes. Diário de Notícias. Porto Alegre, 27 out. 1929. [s.p.].

EDUCAÇÃO physica: a fundação da liga feminina pró-cultura physica. Correio de Povo. Porto Alegre, 28 mar. 1928. [s.p.].

ELIAS, N. Os alemães: a luta pelo poder e a evolução do habitus nos séculos XIX e XX. Rio de Janeiro: Jorge Zahar, 1997.

ESPETÁCUlO em allemão no s. pedro. Correio do Povo. Porto Alegre, 4 ago. 1925. [s.p.].

GOELLNER, S. V. Feminismos, mulheres e esportes: questões epsitemológicas sobre o fazer historiográfico. Movimento, Porto Alegre, v.13, n.2 p. 171-196, maio/ago. 2007.

GUIDO, A. Uma visita ao Instituto de Cultura Physica de Porto Alegre. Diário de Notícias. Porto Alegre, 28 jul. 1929. [s.p.].

GYMNASTICA rytmica e movimentos plasticos. Diário de Notícias. Porto Alegre, 26 set. 1929. [s.p.].

HABRON, J. Through music and into music, through music and into well-being: Dalcroze eurhythmics as music therapy. The Journal for Transdiciplinary Research in Southern África, v. 10, n. 2, p. 90-110, 2014.

HABRON, J. The touch of sound: Dalcroze Eurythmics as a somatic practice. Journal of Dance \& Somatic Practices, v. 7, n. 1, p. 93-112, 2015.

HABRON, J. (Ed.) Proceedings: First International Conference of Dalcroze Studies. Coventry: Coventry University, 2015.

HABRON, J. (Ed.) Proceedings: Second International Conference of Dalcroze Studies. Coventry: Coventry University, 2016

HABRON, J.; MATHIEU, L. Programme: Troisième Congrès international sur les études dalcroziennes. Québec: Université Laval, 2017.

HOFMEISTER FILHO, C. Doze décadas de história. Porto Alegre: SOGIPA, 1987.

HORA de arte. Correio do Povo. Porto Alegre, 20 nov. 1928. [s.p.].

INSTITUTO de cultura física. Correio do Povo. Porto Alegre, 17 nov. 1928. [s. p.].

JESUS, G. Imigrantes desportistas: os alemães no sul do Brasil. Revista Electrónica de Geografía e Ciências Sociales. Scripta Nova: Universidade de Barcelona, 2001. 
LABRA, M.; FIGUEREDO, J. Associativismo, participação e cultura física. O potencial dos conselhos de saúde. Revista Ciência e Saúde Coletiva da Associação Brasileira de PósGraduação em Saúde Coletiva. Rio de Janeiro, 2002.

LYRA, V.; MAZO, J. Z. Nos rastros da memória de um "Mestre de Ginástica". Motriz, Rio Claro, v. 16, n.4, p. 967-976, out./dez., 2010.

LOURO, G. L. Gênero, sexualidade e educação: uma perspectiva pós-estruturalista. Petrópolis: Vozes, 1997.

MAZO, J. Esporte e Educação Física na Revista do Globo: catálogo. Porto Alegre: FEFID/PUCRS, 2004. CD ROM.

MAZO, J. et al. Associações Esportivas no Rio Grande do Sul: lugares e memórias. Novo Hamburgo/RS: FEEVALE, 2012. Versão digital.

MAZO, J. Associativismo esportivo intercultural em Porto Alegre: a fundação dos primeiros clubes teuto-brasileiros no século XIX. In: MORAGAS, M.; DACOSTA, L. (Org.). Universidade e estudos olímpicos: Seminarios España-Brasil 2006. Barcelona: Bellaterra, 2006.

MATHIEU, Louise. Un regard actuel sur la rythmique Jaques-Dalcroze. Recherche en Éducation Musicale, v. 10, p. 17-27, 2010.

MEAD, V. More than mere movement: Dalcroze Eurhythmics. Music Educators Journal, v. 72, n. 6, p. 42-46, 1986.

MUNIZ, M. J. A cultura physica feminina: um appello as nossas patrícias. Correio do Povo. Porto Alegre, 29 mar. 1928. [s.p.].

OLIVEN, R. G. A parte do todo: a diversidade cultural no Brasil Nação. Petrópolis: Vozes, 1992.

PATEK, Claire. A belleza da mulher moderna. Diário de Notícias, Porto Alegre, 11 ago. 1929. [s.p.].

PESAVENTO, S. J. História e história cultural. Belo Horizonte: Autentica, 2008.

PEDRO, J. Mulheres do Sul. In: PRIORI, M. (Org.). História das mulheres no Brasil. São Paulo: Contexto, 1997, p. 278-321.

PFISTER, G. Activités physiques, santé et construction des différences des genres en Allemagne. Clio. Histoire, femmes et sociétés, n. 23, 2006, p. 45-73. Disponível em <http://clio.revues.org/1855\#tocto1n1>. Acesso em: 5 de set. 2017.

PIMENTEL, A. O método da análise documental: seu uso numa pesquisa histórica. Cadernos de Pesquisa, n. 114, p. 179-195, nov. 2001.

PINSKI, C. B. Fontes históricas. São Paulo: Contexto, 2008.

SCOTT, J. Gênero: uma característica útil para a análise histórica. Educação e Realidade, Porto Alegre, v. 20, n. 2, p. 71-99, 1995. 
SCHPUN, M. Beleza em jogo: cultura física e comportamento em São Paulo nos anos 20. São Paulo: Boitempo, 1999.

SCHÜTZ, L. Imigração alemã: processos, costumes e influências. In: SIMPÓSIO DE HISTÓRIA DA COLONIZAÇÃO ALEMÃ NO RIO GRANDE DO SUL. 1. Anais... São Leopoldo, 1974.

SILVA, H. SOGIPA: uma trajetória de 130 anos. Porto Alegre: Palloti, 1997.

SILVA, M. P. A construção/estruturação do gênero na aula de educação física no ensino secundário. 2005. Tese (Doutorado em Ciências do Desporto) - Universidade do Porto, Portugal, 2005.

SOARES, C. L. Educação Física: raízes europeias. Campinas: Autores Associados, 2001.

SUQUET, A. L’éveil des modernités. Paris: Centre National de la Danse/Pantin, 2012.

TESCHE, L. A prática do Turnen entre Imigrantes Alemães e seus descentes no Rio Grande do Sul: 1867-1942. Ijuí/RS: Unijuí, 1996.

UMA OBRA grandiosa a realizar-se no Rio Grande do Sul. Diário de Notícias, Porto Alegre, 11 ago. 1929. [s.p.].

VIGARELLO, G. Exercitar-se, jogar. In: CORBIN, A.; COURTINE, J.; VIGARELLO, G. História do corpo: da Renascença às Luzes. Petrópolis: Vozes, 2008, p. 303-319.

VOGT, O. A colonização alemã no Rio Grande do Sul e o capital social. 2006. Tese (Doutorado em Desenvolvimento Regional) - Universidade de Santa Cruz do Sul, Santa Cruz do Sul, 2006.

Recebido em: 17/05/2016

Revisado em: 28/08/2017

Aprovado em: 02/11/2017

Endereço para correspondência:

modantas67@gmail.com

Mônica Fagundes Dantas

Universidade Federal do Rio Grande do Sul, Departamento de Educação Física

Rua Felizardo, 750

Jardim Botânico

90690-200 - Porto Alegre, RS - Brasil 